\title{
FRAGILIDADE AMBIENTAL URBANA
}

\author{
urban environmental fragility \\ Jader de Oliveira Santos ${ }^{1}$ \\ Jurandyr L. S. Ross ${ }^{2}$ \\ $a_{a} \boldsymbol{a}_{a} a$
}

\begin{abstract}
Resumo
A questão ambiental urbana nas cidades brasileiras apresenta um quadro bastante problemático. Referidos problemas são derivados de um modelo de crescimento que não considerou as limitações impostas aos ambientes de maior fragilidade, desencadeando uma série de conflitos socioambientais. Devido à pertinência da temática, emerge a necessidade do desenvolvimento de estudos ambientais integrados para compreender e dimensionar a problemática ambiental urbana. Busca-se com este artigo demonstrar que a fragilidade ambiental constitui eficiente instrumento de investigação em ambientes urbanizados, fornecendo subsídios para a implementação de estratégias e ações visando à redução dos problemas socioambientais urbanos. Para tanto, utiliza-se como exemplo de aplicação dessa metodologia a investigação da fragilidade ambiental na cidade de Fortaleza-Ce.
\end{abstract}

Palavras-chave: Fragilidade ambiental, Análise ambiental integrada, Ambiente urbano.

\begin{abstract}
The urban environmental issue in Brazilian cities presents a quite problematic picture. Such problems are derived from a growth model that did not consider the limitations imposed on the most fragile environments, triggering a series of socioenvironmental conflicts. Due to the relevance of the subject, the need of the development of integrated environmental studies emerges in order to comprehend and scale the urban environmental problematic issue. This article seeks to show that the environmental fragility constitutes an effective investigative tool in urbanized environments, providing subsidies for implementing strategies and actions to the reduction of urban socioenvironmental issues. Therefore, it is used as an example of application of this methodology the investigation of the environmental fragility in the city of Fortaleza-Ce.
\end{abstract}

Key words: Environmental fragility, Integrated analysis, Urban environment.

\section{Résumé}

La question environnementale urbaine dans les villes brésiliennes c'est assez problématique. A cause d'un modèle de croissance absolument négligent par rapport à la fragilité de certains milieux, le résultat c'est une gamme de conflits socio-environnementales. Grâce à la pertinence de ce sujet, il faut développer des études environnementaux intégrés afin de souligner sa complexité. Dans ce contexte, on veut signaler l'importance de la notion de fragilité environnementale en ce qui concerne à l'aménagement de milieux urbains. Pour cela, notre étude de cas est la ville de Fortaleza-CE.

Mots-Clés: Fragilité Environnementale; Analyse Environnementale Integrée; Milieu Urbain

(1) Prof. Dr. da Universidade Federal Rural do Rio de Janeiro - BR-465 km7, CEP: 23890-000 - Seropedica (RJ), Brasil. Tel.: (+55 21) 37873673 - jader.santos@gmail.com

(2) Prof. Dr. da Pós-Graduação em Geografia da Universidade de São Paulo - Av. Prof. Lineu Prestes, 338. CEP: 05508-900 Sao Paulo (SP), Brasil. Tel.Fax: (+55 11) 3091-8560 / (+55 11) 3091-3769 - juraross@usp.br

\section{aaAaa}

Revista da ANPEGE, v. 8, n. 10, p. 127 -144, ago./dez. 2012.

ISSN 1679-768 X @ (2003, Associação Nacional de Pesquisa e Pós-Graduação em Geografia. Todos os direitos reservados. 


\section{INTRODUÇÃO}

Ao se apropriar do território e dos recursos ambientais a sociedade promove significativas transformações no ambiente natural para atender seus anseios e necessidades. Essas mudanças, muitas vezes, ocorrem de forma desordenada, sem considerar as limitações impostas aos ambientes de maior fragilidade, desencadeando impactos e riscos emergentes. Tais problemas trouxeram as questões ambientais para o centro das atenções na sociedade contemporânea, despertando ações e embates entre segmentos sociais com visões amplamente divergentes.

Esses conflitos nada mais são do que a exposição da complexidade da questão ambiental e de como essa repercute no ordenamento do território. Referido debate suscitou a necessidade do desenvolvimento de estudos ambientais integrados de modo a compreender a complexidade das relações sociedade-natureza, como estas se materializam nos territórios e quais as consequências dessas intervenções no ambiente natural e/ou modificado pelas atividades humanas.

A partir da segunda metade do século XX vários autores passaram a discutir abordagens integradas em geografia estabelecendo avaliações multitemáticas que consideram etapas analíticas, integrativas e sintéticas. Referidas análises partem das relações de interdependência entre as componentes socioambientais numa perspectiva de totalidade. Dentre os autores que tratam da temática merecem destaque os trabalhos de Tricart (1977, 1992), Sotchava (1976), Grigoriev (1968), Bertrand (1969), Guerasimov (1980), Ab'Saber (1969, 1994), Christofoletti (1979, 1999), Ross (1994, 1995, 2006), Souza (2000), Rodrigues et al. (2004), dentre tantos outros.

Essas investigações apresentam em comum a necessidade do desenvolvimento de estudos ambientais aplicados ao uso e exploração dos recursos ambientais, bem como para a gestão ambiental e ordenamento do território. Por trazerem à tona as relações de interdependência e de funcionalidade entre as componentes ambientais, essas abordagens, constituem um novo paradigma na análise geográfica, pois permitem uma abordagem integradora entre a sociedade e a natureza.

Embora exista um amplo arcabouço teórico, metodológico e conceitual sobre o desenvolvimento de estudos ambientais integrados, esses não são direcionados ao entendimento da problemática ambiental urbana. Nos aglomerados urbanos as relações entre a sociedade e a natureza são mais conflituosas, pois, são espaços com grande concentração demográfica onde a pressão da sociedade sobre os recursos ambientais é intensa.

De acordo com Acselrad (1999), as articulações entre as questões urbanas e ambientais fazem parte das relações que se dão em torno da apropriação do território e de seus recursos. Essas práticas, a depender do contexto político (resultado das relações de forças entre os segmentos envolvidos), tanto podem promover um processo de melhoria das condições de vida (pautado nos preceitos de justiça ambiental), como podem ampliar os conflitos ambientais e territoriais.

Tais concepções evidenciam que o ambiente urbano é resultado de um longo processo que envolve os aspectos da sociedade e de como ela se relaciona com o meio. Corroborando essa ideia Brandão (2001, p. 56) assim esclarece:

O meio ambiente urbano é um sistema altamente interrelacionado, em que tanto os elementos que são obra do homem como os elementos naturais são considerados parte do sistema de relações e que os resultados (bons e ruins) são fruto da combinação dos dois.

$\mathrm{O}$ atual quadro urbano-ambiental das cidades brasileiras mostra que essas relações se dão de forma desordenada, desencadeando enorme quantidade de problemas e conflitos socioambientais. O Brasil passou por intensa transformação que promoveu profundas mudanças na distribuição da população no território. Santos (2008) explica que até a primeira metade do século XX o País era uma nação com população predominante rural, e que entre 1940 e 1980 é que se dá a verdadeira inversão do lugar de residência da população. Segundo o autor num período de apenas quatro de- 
cênios, a população urbana passa de 25,73\% do total em 1940 para em 1980 chegar a 67,69\% da população vivendo nas cidades.

Maricato (2001) explica que um crescimento de tamanha envergadura constitui um gigantesco movimento de construção de cidades detentoras de uma variedade de problemas que exercem uma enorme pressão sobre os ambientes naturais. Sobre o rápido crescimento urbano Santos (2008) chama atenção que embora possam se manifestar com variações na forma e na intensidade esses problemas apresentam características comuns a todas as cidades brasileiras. Ressalta ainda que esse fenômeno é uma das características mais marcantes da urbanização nos países em desenvolvimento, assumindo proporções avassaladoras para essas nações em meados da década de 1980.

A partir dessas considerações percebe-se que o crescente aumento das pressões da sociedade sobre o meio natural torna cada vez mais necessário um processo continuado de planejamento e gestão, cujo objetivo primordial é o ordenamento do território; ordenamento este que deve considerar tanto a dinâmica ambiental como a complexidade das relações de uma sociedade desigual. Isto faz com que o planejamento e a gestão (ambiental e territorial) devam ser realizados de modo que nenhum desses dois aspectos (ambiental e social) seja negligenciado.

Com arrimo nessa concepção, é possível perceber a necessidade da realização de estudos integrados que, de um lado, considerem as fragilidades dos ambientes naturais e, de outro, as potencialidades dos ambientes e das sociedades humanas.

A fragilidade ambiental é uma metodologia de investigação que tem como finalidade fornecer a análise das componentes ambientais de forma integrada, sinteticamente tratadas e representadas no território. Presume que a identificação dos ambientes e suas fragilidades potenciais e emergentes permite a melhor definição das diretrizes e ações a serem implementadas no espaço físico-territorial (ROSS, 1995). A esse respeito Ross $(1994$, p. 63) fala que é indispensável "que as intervenções humanas sejam planejadas com objetivos claros de ordenamento territorial, tomando-se como premissas a potencialidade dos recursos naturais e humanos e as fragilidades dos ambientes".

Evidencia-se, portanto, que as unidades de fragilidade são um importante instrumento de subsídio ao planejamento e ordenamento territorial. Embora considere que os seres humanos são o ponto central da questão ambiental, em sua formulação inicial, a análise da fragilidade não foi concebida para aplicação em áreas metropolitanas ou ambientes fortemente urbanizados.

Ante essas condições surgem algumas questões: como conduzir estudos ambientais integrados em áreas que já passaram por um processo de urbanização ou que sofrem com as pressões advindas das transformações urbanas? Em que medidas estes estudos podem fornecer subsídios para um adequado processo de ordenamento do território de modo a reduzir os problemas socioambientais?

Justamente nesse sentido, o presente artigo se apresenta ao propor a utilização desse tipo de investigação nos ambientes urbanos. As formulações aqui apresentadas são o resultado da experiência acumulada em investigações acadêmicas e de estudos destinados a subsidiar planos de manejo em unidades de conservação, zoneamentos ecológico-econômicos e planos diretores de desenvolvimento urbano.

Para a validação das considerações aqui expostas usa-se como exemplo a análise da fragilidade ambiental na Cidade de Fortaleza, capital do Estado do Ceará. Trata-se de uma metrópole com população superior a dois milhões e quatrocentos mil habitantes, que embora apresente elevado estágio de transformação dos ambientais naturais, em alguns setores guarda características intrínsecas desses ambientes.

\section{DA ECODINÂMICA À FRAGILIDADE AMBIENTAL: PRINCÍPIOS E CONCEPÇÕES}

Investigações que objetivam realizar estudos integrados, como é o caso da fragilidade ambiental, em sua grande maioria, estão sustentadas em concepções teóricas e metodológicas que consideram, de um lado, a estrutura e funcionamento do meio físico natural e, de outro, as intervenções promovidas pelas atividades produtivas e culturais. Com base nesses princípios, busca-se estabelecer o 
inter-relacionamento entre os sistemas naturais e socioeconômicos que revelam diversos aspectos das relações sociedade e natureza.

Com efeito, a análise geográfica tem papel de destaque, pois, de acordo com Guerasimov (1980), a geografia é a ciência que estuda o ambiente numa perspectiva de totalidade ao envolver as condições bióticas e abióticas, enfatizando as relações de interdependência entre as componentes ambientais e sociais configurando diferentes paisagens.

Para Ab'Saber (1994) a paisagem é o suporte ecológico e bioecológico modificado por uma infinidade de combinações de obras e atividades promovidas pela sociedade. Segundo Grigoriev (1968), as paisagens geográficas são manifestações de leis físico-geográficas associadas às características locais, sobremaneira influenciadas por meio das atividades antropogênicas. Ainda na expressão do autor, ao modificar a natureza para atender seus anseios e necessidades, o homem modifica sua própria natureza.

Tricart (1977) afirma que o homem participa efetivamente dos ambientes onde vive, modificando-os, permanentemente, para atender seus anseios e necessidades. Ao enfatizar a importância das relações intrínsecas estabelecidas entre a sociedade e a natureza, Ross (1994, p.64-65) ensina que as sociedades humanas não devem ser tratadas como elementos estranhos à natureza, e, portanto, aos ambientes onde vivem; ao contrário, devem ser vistas como parte fundamental da dinâmica que fazem o sistema como um todo funcionar, enfatizando que:

As progressivas alterações até então inseridas pelas sociedades humanas nos diferentes componentes naturais, afetam cada vez mais a funcionalidade do sistema e com frequência induzem a graves processos degenerativos ao ambiente natural, em um primeiro momento, e a própria sociedade em prazos mais longos.

Essas interferências variam conforme o grau de desenvolvimento tecnológico e dos processos histórico-culturais de determinada sociedade, desencadeando adaptações no ambiente para que esse possa se adequar a essas mudanças. $\mathrm{O}$ entendimento desse imbricado jogo de relações só pode ser alcançado mediante a realização de estudos integrados que consideram a complexidade dessas relações numa perspectiva analítica, integradora e sintética.

Ross (2006), ao tratar das análises integradas sugere que uma abordagem sistêmica permite investigar os fenômenos ambientais e suas inter-relações que se caracterizam por dinâmicas em fluxos constantes de energia e matéria em partes de um todo indissociável. Porto $(2007$, p. 50) reforça o caráter integrador desse tipo de investigação ao lecionar que

As abordagens sistêmicas são de grande importância para análises integradas por sintetizarem e ilustrarem, através de modelos esquemáticos, aspectos essenciais do problema analisado. Representações sistêmicas podem fornecer uma visão sinóptica dos problemas, que permite ver de uma só vez as diversas partes de um conjunto. Isto propicia uma visão geral dos diversos componentes, estruturas e processos que formam a cadeia global de interações e causas-efeitos, facilitando, desta forma, a definição e implementação de políticas e estratégias mais abrangentes.

A análise ambiental integrada dá ênfase ao conhecimento integrado e a delimitação dos espaços territoriais, modificados ou não pelos fatores socioeconômicos e culturais, que tem por finalidade a geração de produtos sintéticos e analíticos cujos conteúdos devem necessariamente apresentar informações multitemáticas e ser especializados no território (ROSS, 1995, 2006; SOUZA, 2000; SOUZA et al., 2009). Ainda na concepção dos autores essas informações devem resultar na identificação e delimitação de espaços territoriais com base nos quais possa ser formulado o entendimento das potencialidades e fragilidades dos sistemas socioambientais e dos grupos sociais que habitam esses espaços. 
Esse tipo de abordagem constitui um novo paradigma na análise geográfica, permitindo superar a fragmentação analítica imposta pelas diversas áreas do conhecimento científico. A esse respeito Ross (2006, p. 20) diz que

O domínio desse novo paradigma socioambiental é um objeto riquíssimo, não mais da Geografia física, da Geografia humana, da Geomorfologia, da Climatologia, entre outros ramos, mas sim, da Geografia, da abordagem analítico-integradora e sintetizadora de uma Geografia que se preocupa com o 'espaço total'.

A concepção de espaço total segue os delineamentos de Ab'Saber (1994) que definiu o espaço total como todo mosaico de componentes introduzidos pelas sociedades ao longo da história de uma paisagem, considerada como parte integrante de um território. A gênese do espaço total considera a análise da estruturação espacial realizada pela sociedade sobre os atributos remanescentes de um espaço herdado da natureza.

Ross (2006) diz que o espaço total envolve uma abordagem geográfica de maior espectro, cujas análises ultrapassam o entendimento das potencialidades dos recursos ambientais, envolvendo as potencialidades humanas e as fragilidades dos sistemas ambientais naturais e das sociedades humanas.

A análise da fragilidade do ambiente é uma proposta de classificação cujo princípio básico é definir os diferentes níveis de fragilidade dos ambientes naturais e/ou modificados pelas atividades antropogênicas em face do desenvolvimento das atividades humanas. As unidades de fragilidade ambiental são importante instrumento de subsídio ao planejamento ambiental e territorial, já que "a identificação dos ambienteis naturais e suas fragilidades potenciais e emergentes permite melhor definição das diretrizes e ações a serem implementadas no espaço físico-territorial". (ROSS, 1995, p. 73).

A definição dessas unidades considera as diferentes formas de uso e exploração dos recursos ambientais e compartilha conceitos e princípios da ecodinâmica. O conceito de unidade ecodinâmica é integrado à ideia de ecossistemas, com base no instrumento lógico dos sistemas, onde são enfocadas as relações mútuas entre os diversos componentes da dinâmica ambiental e os fluxos de matéria e energia existentes no meio ambiente (TRICART, 1977). Ainda segundo autor, essa abordagem é voltada ao melhor aproveitamento dos recursos ambientais, de forma que sua exploração não ultrapasse a capacidade de suporte do ambiente.

Embora em suas considerações teóricas Tricart não mencione a Teoria do Equilíbrio Dinâmico, Fierz (2008) destaca o fato de que, com a ecodinâmica, Tricart foi um dos autores que conseguiu aproximar os preceitos estabelecidos na Teoria do Equilíbrio Dinâmico de uma aplicação.

Sobre concepção de unidades ecodinâmicas Ross (1994, p. 65) ensina que,

Dentro desta concepção ecológica o ambiente é analisado sob o prisma da Teoria dos sistemas que parte do pressuposto de que na natureza as trocas de energia e matéria se processam através de ralações em equilíbrio dinâmico. Esse equilíbrio, entretanto, é frequentemente alterado pelas intervenções do homem nas diversas componentes da natureza, gerando estado de desequilíbrios temporários ou até permanentes.

Para definição das unidades ecodinâmicas, no entanto, Tricart (1977) considerou essencialmente a relação entre os processos morfogenéticos e pedogenéticos. Segundo o autor, mediante aferição do balanço entre a morfogênese e a pedogênese, é possível qualificar a ecodinâmica das paisagens, definindo a maior ou menor estabilidade dos ambientes em decorrência da intensidade dos processos atuais. Quando a relação for predominantemente favorável à pedogênese, maior estabilidade será conferida ao ambiente, o que lhe assegurará estado mais avançado de estabilidade. Quando a morfogênese predominar, configura tendência a um ambiente ecodinamicamente instável. Nos casos em que pode prevalecer a manifestação ativa e intensa dos processos pedogenéticos e dos processos morfogenéticos simultaneamente, configuram-se os ambientes de transição.

Nessa perspectiva, foram propostos três meios ecodinâmicos: estáveis, de transição (intergrades) e fortemente instáveis, os quais serão sinteticamente caracterizados: 
Os ambientes estáveis são aqueles em que os processos pedogenéticos predominam em relação aos processos morfogenéticos. O modelado evolui lentamente, com fraca atuação dos processos mecânicos. A estabilidade morfogenética é antiga, devido ao baixo potencial erosivo. Consequentemente, há um recobrimento vegetal bem desenvolvido e pouco alterado pelas atividades socioeconômicas, assemelhando-se às condições vegetacionais originais, o que corresponderia ao "clímax", ou onde a vegetação está em decurso avançado de regeneração. Nos ambientes que apresentam essas condições, há equilíbrio entre a exploração dos recursos e a capacidade produtiva dos sistemas.

Ambientes de transição ou intergrades caracterizam-se pela ocorrência simultânea da morfogênese e da pedogênese. De tal modo, a formação de solos ou de relevo encontra-se numa relação que pode favorecer a uma ou a outra condição. Quando há predomínio da morfogênese, a ecodinâmica é de transição com tendências à instabilidade. Quando os processos pedogenéticos são mais atuantes, ocorre um ambiente de transição com tendências à estabilidade. Nesse tipo de meio ecodinâmico, o equilíbrio entre a capacidade produtiva e o uso e exploração dos recursos ambientais pode ser facilmente alterado em razão das intervenções ensejadas pelas atividades socioeconômicas, podendo um ambiente passar do estado de transição com tendências à estabilidade para um ambiente de transição com tendências à instabilidade, e, dependendo do grau de alteração, pode chegar à condição de forte instabilidade.

Nos ambientes fortemente instáveis, os processos morfogenéticos são predominantes em relação aos processos pedogenéticos, estando os outros elementos do sistema natural subordinados à morfogênese. A atividade dos processos erosivos é intensa, por vezes acarretando o exaurimento da capacidade produtiva dos recursos naturais. Nessas situações, as reservas paisagísticas são fortemente comprometidas, chegando, muitas vezes, à condição de irreversibilidade, com rupturas do equilíbrio ecológico, remoção dos solos e impossibilidade de manutenção da atividade biológica e do desenvolvimento de atividades socioeconômicas.

Ross et al. (2008) expressam que esses pressupostos atendem perfeitamente a uma perspectiva de planejamento agronômico-ambiental, que embora válida, não atende suficientemente os propósitos voltados para um planejamento ambiental de aspecto mais amplo, que privilegie a dinâmica e as demandas das sociedades humanas nos seus aspectos econômicos, culturais e políticos.

Ao tratar essencialmente dos processos físico-ambientais, a ação das sociedades humanas é negligenciada, tornando-a de difícil aplicação em áreas urbanizadas, onde o grau de complexidade é maior em virtude das interferências produzidas pelos diferentes níveis de desenvolvimento tecnológico, econômico e cultural. Outro aspecto a ser considerado é a ênfase conferida aos processos externos, o que acaba por negligenciar a dinâmica dos processos endógenos, que em muitos casos, assumem significativa importância.

Por fim, o estabelecimento de apenas três meios ecodinâmicos reduz em muito as possibilidades de utilização dessa metodologia, pois por mais que o ambiente esteja em estágio de estabilidade, ele tende à instabilidade, principalmente se consideradas as transformações das sociedades humanas. Deste modo, são encontradas limitações à ampla utilização da ecodinâmica aos estudos geográfico-ambientais com vistas ao planejamento.

De modo a tentar superar essa limitação Ross (1994) ampliou o conceito de unidades ecodinâmicas ao estabelecer as unidades de instabilidade em potencial e as unidades de instabilidade emergente, classificando-as em cinco níveis hierárquicos, variando de muito fraca a muito forte. Para tanto, desconsiderou os meio intergrades em face da imprecisão de definição dessa unidade e inseriu novos critérios de classificação para as unidades ecodinâmicas estáveis e unidades ecodinâmicas fortemente instáveis.

As unidades de fragilidade potencial, grosso modo, correspondem aos ambientes estáveis que se encontram em condições de equilíbrio dinâmico, portanto, que foram menos afetados pelas ati- 
vidades humanas. Embora apresentem condições de ambientes estáveis, apresentam instabilidade potencial qualitativamente previsível face as suas características naturais e ao desenvolvimento das atividades humanas (ROSS, 1994).

Ao mesmo tempo, as unidades de fragilidade emergente estão associadas aos ambientes fortemente instáveis, ou seja, onde não se configuram as condições de equilíbrio dinâmico. Sobre a dinâmica dos ambientes fortemente instáveis, Ross et al. (2008, p. 71) apresentam que

Os ambientes instáveis são assim caracterizados por notáveis mudanças das formas, frequentemente alterações sazonal, crônica ou catastrófica, devido a um importante fluxo de material principalmente grosseiro, mas não necessariamente. São várias as causas dos ambientes instáveis, tais como as forças internas como fortes tremores de terra, condicionando deslizamentos de terras, fluxos de lamas, avalanches de neve e gelo, fluxo de lavas vulcânicas. Condições bioclimáticas também são causas de instabilidade. Irregularidade climática é em geral um sério limitante fator ecológico, bem como as intervenções das sociedades humanas que ao se apropriarem dos recursos ecológicos no ambiente geram instabilidade morfodinâmica em diferentes níveis ou graus.

Embora possam ser naturalmente frágeis, as unidades de fragilidade emergente se caracterizam por serem aquelas cujas intervenções antropogênicas modificaram intensamente o ambiente natural, afetando significativamente a dinâmica ambiental.

Tanto as unidades de fragilidade potencial como as unidades de fragilidade emergente são hierarquizadas numa classificação qualitativo-numérica que varia de muito baixa (1), baixa (2), média (3), forte (4) e muito forte (5), apresentadas na tabela 1.

Tabela 1 - Classificação das unidades de fragilidade

\begin{tabular}{|c|c|c|}
\hline \multirow{2}{*}{ UNIDADES DE FRAGILIDADE } & \multicolumn{2}{|c|}{ CLASSIFICAÇÃO DOS NÍVEIS DE INTENSIDADE DA FRAGILIDADE } \\
\hline & QUALITATIVA & NUMÉRICA \\
\hline \multirow{5}{*}{ 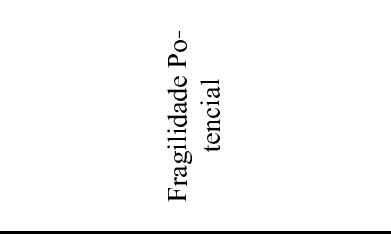 } & Muito baixa & 1 \\
\hline & Baixa & 2 \\
\hline & Média & 3 \\
\hline & Forte & 4 \\
\hline & Muito forte & 5 \\
\hline \multirow{5}{*}{ 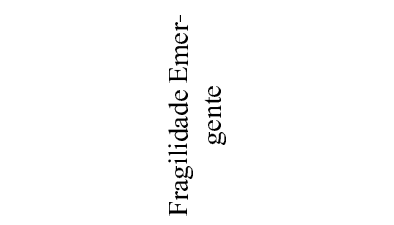 } & Muito baixa & 1 \\
\hline & Baixa & 2 \\
\hline & Média & 3 \\
\hline & Forte & 4 \\
\hline & Muito forte & 5 \\
\hline
\end{tabular}

Fonte: Ross (1994).

Segundo Ross et al. (2008, p.73), a redefinição das unidades ecodinâmicas foi fruto do atendimento das necessidades decorrentes dos projetos de planejamento para bacias hidrográficas, bem como para investigações e resolução de problemas em áreas com inundações, a esse respeito, falam que

A utilização dos conceitos de Tricart (1977) despertou em Ross (1990 e 1994) a percepção de diferentes níveis de fragilidade dos sistemas ambientais e as características naturais de um lado e de outro o potencial de uso socioeconômico dos recursos naturais. Assim surgiu a concepção de fragilidade ambiental, com análises integradas das relações sociedade-natureza, onde se admite como princípio lógico que os seres humanos são o centro das preocupações e que as questões ambientais são antes de tudo socioculturais.

O reconhecimento das potencialidades e fragilidades dos recursos naturais passa necessariamente pelos levantamentos de solos, clima, rochas, minerais, águas, flora e fauna, enfim de todas as 
componentes da natureza; no entanto, a análise da fragilidade exige que esses componentes sejam avaliados de forma integrada, ancorados numa perspectiva sistêmica que parte do pressuposto de que na natureza a funcionalidade é intrínseca, envolvendo as componentes físicas, bióticas e socioeconômicas, como bem explica Ross (1995, p. 73).

A identificação dessas unidades tem como objetivo principal fornecer informações dos componentes da natureza de forma integrada, sinteticamente tratadas e representadas em áreas homogêneas. Este produto cartográfico deve representar nos diferentes ambientes naturais, as suas fragilidades potenciais e emergentes e as áreas de riscos (deslizamentos, inundações etc).

Ante as considerações que foram apresentadas, fica evidente que a maior ou menor fragilidade ambiental não é dependente de um só fator, mas de um conjunto de fatores que determinam a capacidade de resiliência do ambiente que é, antes de tudo, a vulnerabilidade que esse sistema apresenta às intervenções humanas (SANTOS, 2006). Em síntese, a análise da fragilidade ambiental exige que os conhecimentos setorizados pelas diversas disciplinas científicas sejam avaliados de forma integrada.

\section{PROPOSTA DE CLASSIFICAÇÃO DA FRAGILIDADE PARA AMBIENTES URBANOS}

A análise da fragilidade ambiental passa necessariamente por atividades de campo e escritório e envolve etapas que conduzem a estudos básicos do relevo, solo, subsolo, uso do território e do clima. Com base neles, são gerados produtos intermediários, mediante relatórios e/ou cartografia temática e sintética (ROSS, 1994).

Dentre os produtos intermediários, a carta geomorfológica é um dos produtos de maior importância para a elaboração do mapa de fragilidade ambiental.

Segundo Ross $(1992,2003)$ o mapa geomorfológico deve representar em primeiro plano as formas de diferentes tamanhos e em planos secundários, a representação da morfometria, morfogênese e morfocronologia, que têm vínculo direto com a tipologia das formas. Estas considerações estão pautadas no princípio que tanto o estrutural como o escultural estão presentes em qualquer tamanho e forma de relevo e que suas categorias de tamanho, formas, idades e gêneses são passíveis de ser individualizadas e cartografadas em categorias diferentes conforme a escala de análise, o que permite classificar o relevo terrestre em seis unidades taxonômicas. Referida classificação leva em conta os princípios definidos por Penk (1953) relativos aos processos endógenos e exógenos e os conceitos de Guerasimov (1980) e Mecerjakov (1968) sobre morfoestrutura e morfoescultura.

A definição da fragilidade do relevo em escalas médias e pequenas segue como parâmetro a definição dos padrões de formas com a rugosidade topográfica ou a matriz dos índices de dissecação do relevo que consideram a dimensão interfluvial média no plano horizontal e o grau de entalhamento dos vales no plano vertical (ROSS, 1994). Para investigações que exigem um nível maior de detalhamento o autor propõe a utilização das classes de declividade, sugerindo que sejam utilizados os intervalos de classes já consagrados nos estudos de aptidão agrícola associados com aqueles conhecidos como valores limites críticos da geotecnia, indicativos dos riscos da ocorrência de escorregamentos/deslizamentos e inundações frequentes.

Em ambientes urbanos, onde as alterações de ordem antropogênica são bastante acentuadas devem ser utilizadas classes de declividade que considerem as especificidades do sítio urbano em investigação, permitindo assim, auxiliar na definição da fragilidade ambiental. A tabela 02 traz a relação entre as classes de declividade apresentadas na proposta original e as que foram utilizadas na definição da fragilidade do relevo para o sítio urbano de Fortaleza.

As classes de fragilidade dos solos passam necessariamente pelo conhecimento das características de textura, estrutura, plasticidade, grau de coesão das partículas, profundidade e espessura dos horizontes superficiais e subsuperficiais, diretamente relacionadas com o relevo, a litologia e o 
clima. Com base nessas características e ao considerar o escoamento superficial das águas pluviais, tanto no aspecto difuso como concentrado, podem ser estabelecidas as classes de fragilidade dos solos. Ross (1992) considerou uma série de análises realizadas por diferentes autores que tratam da erodibilidade dos solos e sintetizou hierarquização da fragilidade dos solos, alertando para a necessidade de adaptações em razão das diferenças de solos existentes nas diferentes regiões do Brasil.

Tabela 2 - Categorias hierárquicas de declividade

\begin{tabular}{c|c|c|}
\hline \multirow{2}{*}{$\begin{array}{c}\text { CATEGORIAS HIE- } \\
\text { RÁRQUICAS }\end{array}$} & \multicolumn{2}{|c|}{ DECLIVIDADES EM \% } \\
\cline { 2 - 3 } & $\begin{array}{c}\text { PROPOSTA ROSS } \\
(1994)\end{array}$ & $\begin{array}{c}\text { PROPOSTA ADAP- } \\
\text { TADA }\end{array}$ \\
\hline 1. Muito fraca & 0 a $6 \%$ & 0 a $3 \%$ \\
\hline 2. Fraca & 6 a $12 \%$ & 3 a $8 \%$ \\
\hline 3. Média & 12 a $20 \%$ & 8 a $13 \%$ \\
\hline 4. Forte & 20 a $30 \%$ & 13 a $20 \%$ \\
\hline 5. Muito forte & maior que $30 \%$ & maior que $20 \%$ \\
\hline
\end{tabular}

Fonte: adaptado de Ross $(1992,1994)$

Embora válida esse tipo de classificação se destina à definição da fragilidade dos solos em ambientes predominantemente rurais. Em ambientes urbanizados faz-se necessário considerar como os diferentes estágios de urbanização interferem na classificação da fragilidade dos solos. Tal preocupação se faz premente, visto que nas áreas metropolitanas os solos em sua grande maioria foram alterados por aterros e compactações e/ou encontram-se sobrepostos por impermeabilização asfáltica, o que altera o comportamento do solo em face da ação da chuva/erosão e seu suporte às construções. Considerando essa especificidade, foi elaborada uma proposta de classificação da fragilidade dos solos que harmoniza a este tipo de investigação em áreas urbanas, apresentada na tabela 3.

Tabela 3 - Fragilidade dos solos considerando os efeitos da urbanização

\begin{tabular}{|c|c|}
\hline $\begin{array}{l}\text { CLASSES DE FRAGILI- } \\
\text { DADE }\end{array}$ & TIPOS DE SOLOS E URBANIZAÇÃO \\
\hline 1. Muito baixa & $\begin{array}{l}\text { Latossolos de estrutura argilosa e média/argilosa (conforme classes } 1 \text { e } 2 \text { da proposta original); Nitosso- } \\
\text { lo, Latossolo vermelho-amarelo em áreas dotadas de infraestrutura urbana. }\end{array}$ \\
\hline 2. Baixa & $\begin{array}{l}\text { Argissolos vermelho-amarelo com textura média/argilosa em áreas urbanas dotadas de boas condições } \\
\text { de infraestrutura. }\end{array}$ \\
\hline 4. Forte & $\begin{array}{c}\text { Argissolos vermelho-amarelos de textura média/arenosa; Neossolos Quartzarênicos em áreas com } \\
\text { infraestrutura urbana. }\end{array}$ \\
\hline 5. Muito forte & Argissolos com cascalhos; Gleissolos; Neossolos flúvicos; e Neossolos Quartzarênicos; \\
\hline
\end{tabular}

Fonte: adaptado de Ross (1994) e Ross et al. (2008).

Outro fator importante a ser considerado na fragilidade é o grau de proteção aos efeitos da precipitação. Segundo Ross et al. (2008) o comportamento pluviométrico obedece a uma hierarquização de ordem crescente quanto à capacidade de interferência na estabilidade do ambiente. Um ambiente que apresenta bom estágio de desenvolvimento da cobertura vegetal exibe maior proteção da ação direta das gotas de chuvas em queda livre, ao mesmo tempo em que, onde a vegetação não atenua esse efeito, existe maior susceptibilidade a esse agente morfogênico, portanto, apresenta maior fragilidade. Essa característica assume significativa importância em regiões onde a vegetação 
exerce pouca proteção como acontece no semiárido, e nas zonas costeiras onde não há cobertura vegetal de modo a atenuar os efeitos do transporte eólico.

Assim como acontece com os solos, a proposta original não contempla adequadamente a ação das chuvas nas áreas impermeabilizadas e urbanizadas. No intuito de suprir essa lacuna foi elaborada uma proposta de fragilidade quanto ao grau de urbanização que se aplica às condições do sítio urbano onde foi desenvolvida a investigação apresentada.

A elaboração das categorias de fragilidade quanto à urbanização, partiu do entendimento de que a fragilidade em áreas urbanizadas está relacionada à intensidade do escoamento superficial, possibilidade de infiltração e drenagem após a incidência das chuvas, seja pelas intervenções estruturantes ou pelas condições naturais, susceptibilidade natural à inundação das áreas mais rebaixadas e possibilidade de movimentos de massa. Foram hierarquizadas, portanto, as diferentes tipologias de uso e ocupação do território associado às condições infraestruturais e do ambiente natural. A tabela 04 apresenta de modo sintético os estágios de fragilidade e seus condicionantes fundamentais.

Tabela 4 - Fragilidade quanto ao nível de urbanização

\begin{tabular}{|c|c|}
\hline $\begin{array}{l}\text { GRAUS DE FRA- } \\
\text { GILIDADE }\end{array}$ & NÍVEL DE URBANIZAÇÃO \\
\hline 1. Muito baixa & $\begin{array}{l}\text { Predomínio de condições naturais com um estrato vegetal bem desenvolvido e/ou em estágio de avançado } \\
\text { de regeneração que favorece a infiltração, minimizando o escoamento pluvial. Setores de média urbanização } \\
\text { situados em áreas mais elevadas que apresentam baixa declividade e contam com medidas estruturais e não } \\
\text { estruturais para o controle de cheias, como caixas de sumidouro, canteiros permeáveis, obstáculos para redu- } \\
\text { ção na velocidade do escoamento, reservatórios para coleta e reuso de água de chuva. }\end{array}$ \\
\hline 2. Baixa & $\begin{array}{l}\text { Área urbanizada com drenagem eficiente, baixa declividade, presença de ações para controle de cheias, } \\
\text { infiltração e redução do escoamento nas vias de circulação, nos lotes e nas construções. }\end{array}$ \\
\hline 3. Média & $\begin{array}{l}\text { Área urbanizada predominantemente impermeável com problemas de drenagem e constantes alagamentos e } \\
\text { inundações. Ambientes com declividade praticamente nula precariamente incorporados à drenagem, suscep- } \\
\text { tíveis a inundações sazonais, que podem ter constituído antigas planícies de inundação de corpos hídricos e } \\
\text { lacustres afetados ou não por atividades antropogênicas. }\end{array}$ \\
\hline 4. Alta & $\begin{array}{l}\text { Locais urbanizados e/ou semiurbanizados com precariedade nas construções e na infraestrutura para eventos } \\
\text { pluviométricos de média/baixa intensidade. Áreas de inundação natural, como planícies lacustres, e setores } \\
\text { mais abrigados das planícies fluviais e fluvio-marinhas. }\end{array}$ \\
\hline 5. Muito alta & $\begin{array}{l}\text { Áreas críticas que deveriam ser destinadas à manutenção de sua funcionalidade sistêmica original. Ausência } \\
\text { de infraestrutura e total precariedade dos constructos humanos, fruto do uso e ocupação desordenados do } \\
\text { solo. Ambientes naturalmente favoráveis à inundação, tais como corpos hídricos e planícies de inundação. } \\
\text { Setores com grande declividade susceptíveis a movimentos de massa. }\end{array}$ \\
\hline
\end{tabular}

Fonte: Adaptado de Ross. (1994), Araújo et al. (2005) e Santos (2006).

A grande vantagem da utilização dessa metodologia de classificação da fragilidade ambiental é a possibilidade de emprego dessas variáveis tanto de forma qualitativa, como quantitativa. Desta maneira, pode ser construído um produto cartográfico sintético com a identificação de polígonos de diferentes padrões de fragilidade, representados pelas unidades de fragilidade potencial e unidades de fragilidade emergente.

A preparação desse mapa sintético (fragilidade ambiental) passa pela combinação dos dados e informações anteriormente levantados e produzidos, de modo a envolver os aspectos do relevo, litologia, solos, clima, hidrografia cobertura vegetal e tipos de usos e ocupação, representados através da associação de dígitos arábicos que caracterizam a fragilidade ambiental.

Embora esteja pautada numa perspectiva de indissociabilidade entre as componentes ambientais e suas interações com a sociedade, a classificação ora apresentada utiliza o relevo como elemento fundamental de definição da fragilidade ambiental. Não se trata simplesmente de uma comparti- 
mentação do relevo ou uma análise das formas per si, mas sim da interconexão estabelecida entre o relevo com as demais componentes da natureza, os processos atuantes e as intervenções da sociedade.

Deste modo, a análise da fragilidade ambiental considera a estrutura e funcionamento dos ambientes naturais, levando em conta as transformações promovidas pelas atividades humanas, $o$ que permite definir a capacidade de suporte dos sistemas para o desenvolvimento das atividades produtivas e culturais.

\section{FRAGILIDADE AMBIENTAL EM FORTALEZA}

O estudo de caso para aplicação de classificação da fragilidade em ambientes urbanos foi realizado na cidade de Fortaleza-Ce. Referida cidade encerra um quadro ambiental diversificado, expresso por meio de suas características físico-ambientais, formas de uso e ocupação do território, e exploração dos recursos ambientais. Embora apresente áreas com elevado grau de urbanização, em alguns setores, guarda características intrínsecas de ambientes naturais que servem para amenizar a ação dos eventos de grande magnitude.

O município de Fortaleza, capital do Estado do Ceará, situa-se na porção norte do Estado do Ceará, ocupando uma área de aproximadamente $314 \mathrm{~km}^{2}$ limitando-se ao norte com o oceano Atlântico; ao sul com os Municípios de Maracanaú, Itaitinga e Pacatuba; ao oeste com Eusébio e Aquiraz; ao leste com o Município de Caucaia (figura 1). Trata-se do principal centro urbano cearense, concentrando o maior contingente populacional do Estado com população superior a dois milhões e quatrocentos mil habitantes.

As características geotectônicas e geocronológicas resultam na ocorrência de unidades morfoestruturais que são continuamente atacadas pelos processos exógenos e se traduzem em diferentes padrões de formas de relevo que as representam. Em Fortaleza, esses padrões de formas de relevo se manifestam na primazia das coberturas sedimentares cenozóicas, além dos terrenos cristalinos pré-cambrianos e de rochas vulcânico-alcalinas terciárias (SOUZA, 1988; BRANDÃO, 1995; SOUZA et al., 2009;), que mesmo apresentando variados níveis de fragilidade foram sistematicamente ocupadas, em diferentes níveis de intensidade, ao longo do histórico de construção da cidade.

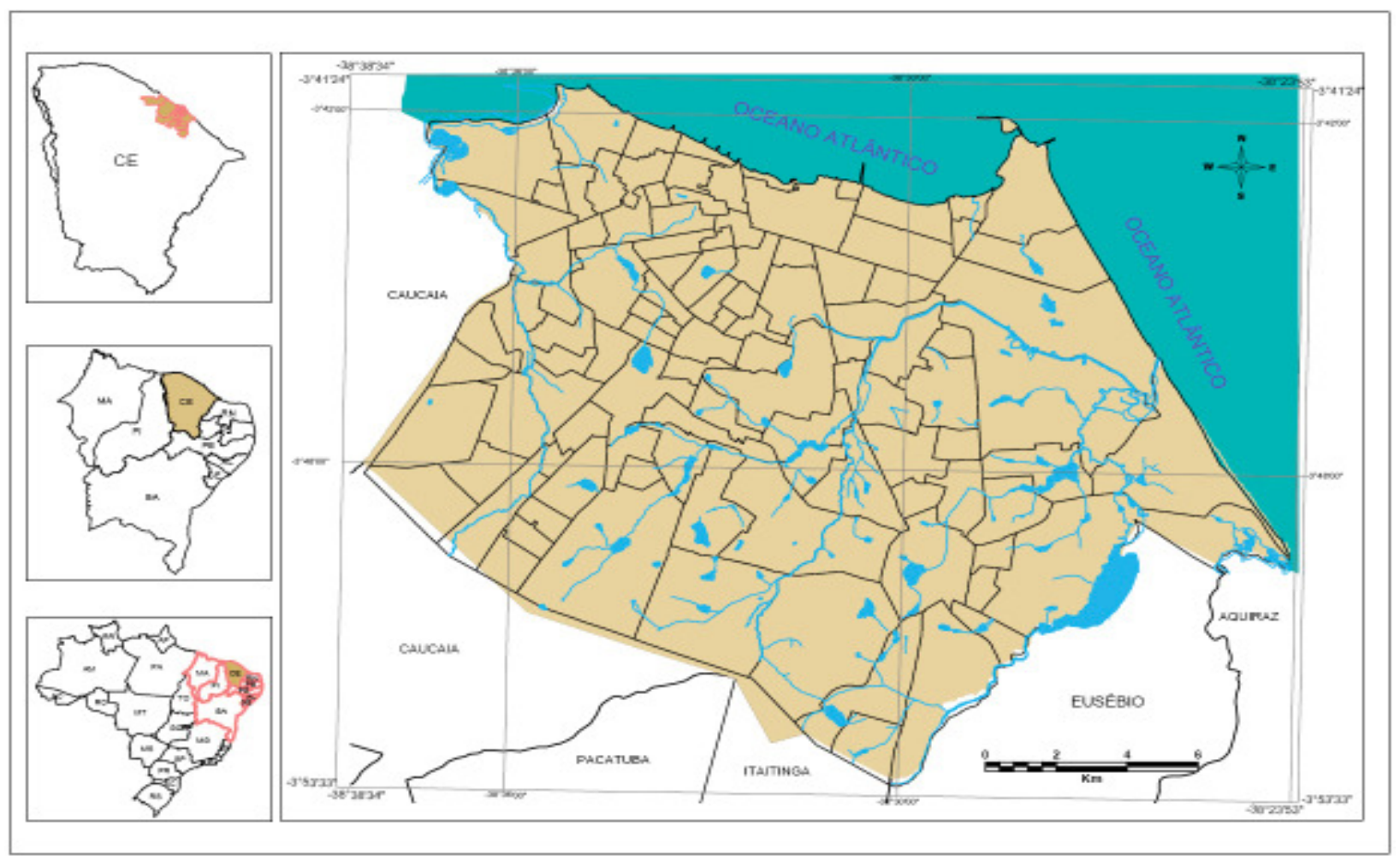

Figura 1 - Localização do município de Fortaleza-CE. 
Embora tenha sido utilizada uma série de informações acerca dos componentes que constituem os diferentes sistemas ambientais, a legenda da fragilidade foi simplificada em uma combinação sequencial numérica, que apresenta os dados referentes ao relevo, ao solo e à ocupação do território.

A atribuição da sequência numérica, bem como o valor representado para cada componente, considera os preceitos estabelecidos para esse tipo de investigação em ambientes urbanizados. Deste modo, os dados na legenda são apresentados numa sequência que varia de 1 (muito fraca) a 5 (muito forte), conforme o grau de fragilidade, se potencial ou emergente.

Optou-se por não utilizar a componente climatológica, visto que em toda sua dimensão o município apresenta certa homogeneidade nas condições climáticas. Trata-se de uma área de pequena extensão territorial (pouco mais de $300 \mathrm{~km}^{2}$ ) onde não se verifica a influência do relevo nas condições de precipitações por meio de chuvas orográficas ou diferenciações de temperatura nos diferentes setores do território. Deste modo todo o clima da área foi considerado como de fragilidade elevada, já que chove mais de $1200 \mathrm{~mm} /$ ano concentrados quase totalmente no primeiro semestre do ano, sobretudo, durante os meses de março a maio, quando da máxima aproximação da Zona de Convergência Intertropical ZCIT (SOUZA, et al., 2009).

O estabelecimento do indicador de fragilidade do relevo foi feito numa perspectiva integrada, não se restringindo aos aspectos morfométricos. Foram considerados, além da forma e declividade, os materiais constituintes e processos atuantes nas formas de relevo.

Em decorrência dessa combinação, a classificação numérica e qualitativa da fragilidade do relevo não seguiu estritamente o definido nas classes de declividade da proposta inicial de Ross (1994). Tal escolha se deu, sobretudo, pelas condições de declividade predominante (entre 0 e $6 \%$ ) e em razão do elevado grau de alteração da paisagem pela urbanização, optando-se assim por um critério mais integrador do relevo com os elementos retromencionados, como foi mostrado na tabela 02.

Especificamente no que se refere à fragilidade dos solos esta foi o resultado das características dos solos aliados aos níveis de transformação do ambiente pelas atividades antropogênicas. Essa definição se deu em virtude do elevado grau de urbanização existente em Fortaleza, onde os solos em muitos casos foram compactados ou estão sotopostos às estruturas urbanas, sobretudo, ao recobrimento asfáltico e infraestrutura viária e urbana como um todo.

A cobertura vegetal e o grau de urbanização constituem o último indicador numérico da fragilidade. Este indicador assume significativa importância, haja vista que a maior ou menor proteção dos solos aos efeitos da energia cinética das gotas de chuva, a capacidade de mobilidade de partículas dos solos e a velocidade e intensidade do escoamento superficial é sobremaneira influenciado pelas condições de cobertura vegetal e o tipo de urbanização.

Ao todo foram encontradas 32 unidades de fragilidade ambiental (o que corresponde a 588 polígonos), agrupadas nas categorias de fragilidade potencial e emergente, sendo 14 de fragilidade potencial e 18 de fragilidade emergente. Um fato a ser destacado é que, com base nos critérios de classificação utilizados, não foram encontrados ambientes de fragilidade muito baixa, tanto nas unidades de fragilidade potencial como nas de fragilidade emergente.

A relação entre as unidades de fragilidade está apresentada na tabela 5 que traz o quantitativo das unidades, dimensão espacial e percentual em relação ao território municipal. Já a figura 2 traz a comparação entre o número de unidades e a área ocupada.

Das 14 unidades de fragilidade potencial, quatro foram consideradas como de baixa fragilidade e estão situadas sobre os tabuleiros pré-litorâneos e paleodunas. Estas quatro unidades ocupam 40\% do território municipal. As unidades de média fragilidade correspondem a $94,83 \mathrm{~km}^{2}(30,20 \%)$, se dividem em sete categorias e estão situadas, principalmente, sobre os tabuleiros e os terrenos cristalinos. Já no que se refere às unidades de forte fragilidade, estas estão divididas em duas categorias, todas situadas no campo de dunas, onde a urbanização já está consolidada. Por fim, as fragilidades potenciais muito fortes situam-se sobre setores dos terraços marinhos, representando apenas uma ocorrência. Estas duas últimas unidades (fragilidade forte e muito forte) são pouco representativas espacialmente e não chegam a 3\% da área do município. 
Tabela 5 - Distribuição da fragilidade em Fortaleza

\begin{tabular}{|c|c|c|c|c|}
\hline \multirow{2}{*}{\multicolumn{2}{|c|}{ UNIDADES DE FRAGILIDADE }} & \multirow{3}{*}{$\begin{array}{c}\text { TOTAL DE UNIDADES } \\
4\end{array}$} & \multicolumn{2}{|c|}{ DISTRIBUIÇÃO NO TERRITÓRIO } \\
\hline & & & \multirow{2}{*}{$\frac{\text { Área }\left(\mathrm{Km}^{2}\right)}{126,76}$} & \multirow{2}{*}{$\begin{array}{c}\text { Percentual } \\
40,37 \%\end{array}$} \\
\hline \multirow{4}{*}{ Fragilidade Potencial } & Baixa & & & \\
\hline & Média & 7 & 94,83 & $30,20 \%$ \\
\hline & Forte & 2 & 3,75 & $1,19 \%$ \\
\hline & Muito Forte & 1 & 3,88 & $1,24 \%$ \\
\hline \multirow{4}{*}{ Fragilidade Emergente } & Baixa & 2 & 2,78 & $0,89 \%$ \\
\hline & Média & 1 & 0,94 & $0,30 \%$ \\
\hline & Forte & 7 & 8,57 & $2,72 \%$ \\
\hline & Muito Forte & 8 & 72,49 & $23,09 \%$ \\
\hline \multicolumn{2}{|l|}{ TOTAL } & 32 & $314 \mathrm{Km}^{2}$ & $100 \%$ \\
\hline
\end{tabular}

Embora as unidades de fragilidade emergente ocupem menor dimensão territorial com cera de $84,7 \mathrm{~km}^{2}$ o que corresponde a $27 \%$ dos $314 \mathrm{~km}^{2}$ do Município, em seu aspecto quantitativo, estas apresentam maior diversidade, fazendo com que sua subdivisão seja mais complexa. Justamente por isso, foram encontrados 18 diferentes tipos de unidades. Destas, duas são classificadas como de baixa fragilidade e apenas uma é considerada de fragilidade média apresentando pequena representatividade espacial (pouco mais de $3 \mathrm{~km}^{2}$ nas duas unidades). Já as que podem ser classificadas como de forte fragilidade correspondem a sete unidades ocupando $8,57 \mathrm{~km}^{2}$. As unidades de situação mais crítica, classificadas enquanto muito forte, são em maior número, com oito ocorrências, representando mais de $23 \%$ do território municipal, com mais de $72 \mathrm{~km}^{2}$ de dimensão.

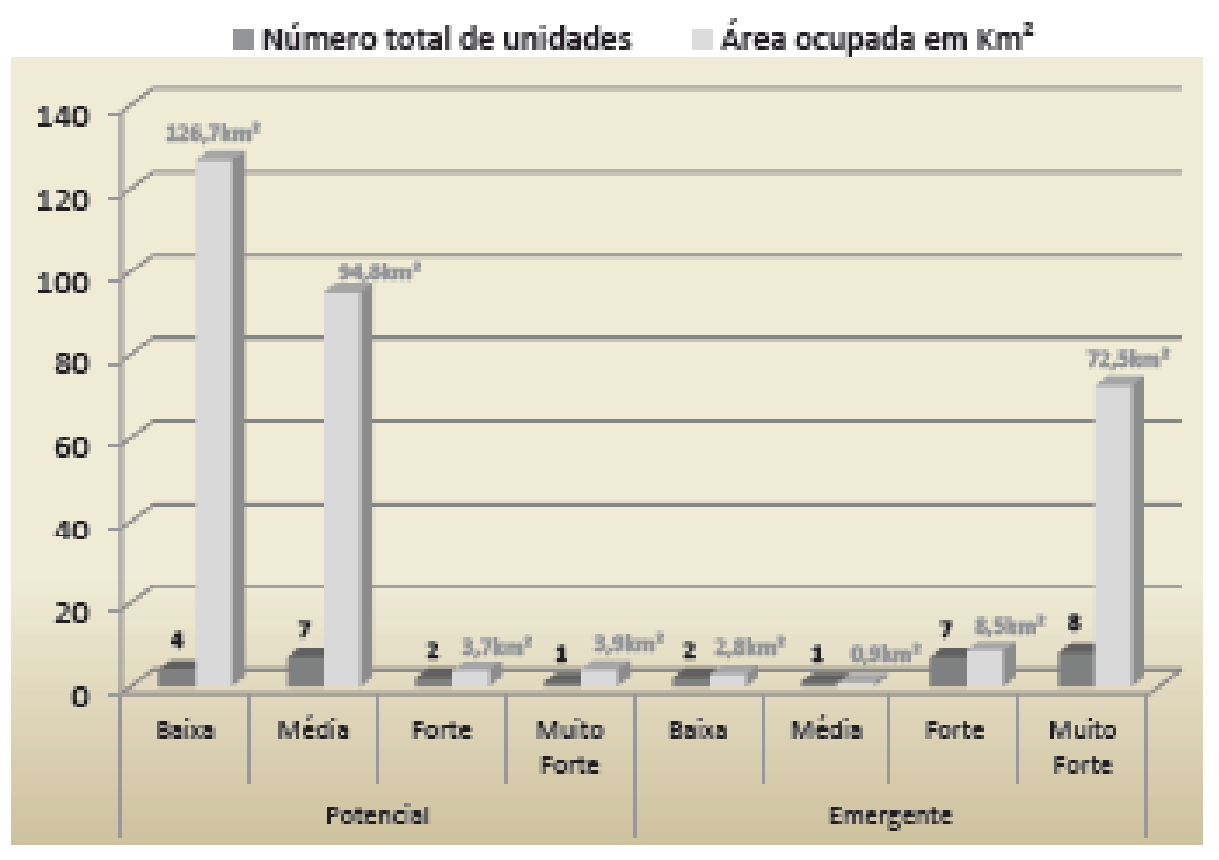

Figura 2 - Quantitativo e distribuição espacial $\left(\mathrm{km}^{2}\right)$ das unidades de fragilidade.

Pode ser destacado um aspecto similar entre esses dois tipos de unidades (forte e muito forte), já que ambas estão situadas predominantemente sobre os terrenos inconsolidados da zona litorânea ou das áreas de acumulação derivadas da dinâmica fluvial e lacustre. 
O quadro 1 apresenta a síntese das unidades de fragilidade, considerando sua categoria (se potencial ou emergente), a unidade (baixa, média, forte e muito forte), compartimento geomorfológico no qual cada unidade está inserida e os indicadores de fragilidade na seguinte sequência: relevo, solos e cobertura. Por fim há o código atribuído a cada unidade.

Quadro 1 - Síntese da fragilidade ambiental

\begin{tabular}{|c|c|c|c|c|}
\hline \multicolumn{2}{|c|}{$\begin{array}{l}\text { CATEGORIAS DE } \\
\text { FRAGILIDADE AMBIENTAL }\end{array}$} & $\begin{array}{l}\text { UNIDADE } \\
\text { GEOMORFOLÖGICA }\end{array}$ & $\begin{array}{l}\text { INDICADORE S } \\
\text { DE FRAGILIDADE }\end{array}$ & $\begin{array}{l}\text { CODDIGOS DE } \\
\text { FRAGILIDADE }\end{array}$ \\
\hline \multirow{9}{*}{ 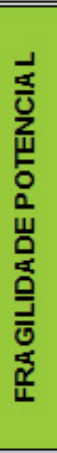 } & \multirow[b]{2}{*}{ BAIXA } & Tabuleiros Pré-litorâneos & 122,222 & Dt122; Dt222 \\
\hline & & Paleodunas & 221,222 & $\begin{array}{l}\text { Adp221, } \\
\text { Adp222 }\end{array}$ \\
\hline & \multirow{5}{*}{ MÉDIA } & Dunas Fixas & 232 & Adf232 \\
\hline & & Tabuleiros Pré-litorâneos & $223,224,232$ & $\begin{array}{l}\text { Dt223; Dt224; } \\
\text { Dt232, }\end{array}$ \\
\hline & & Terraços Marinhos & 232 & Atm232 \\
\hline & & Depressão Sertaneja & 233 & Dp233 \\
\hline & & $\begin{array}{l}\text { Atividades } \\
\text { antropogências } \\
\text { (mineração) }\end{array}$ & 224 & Fam224 \\
\hline & FORTE & Dunas Fixas & 332,333 & Adf332; Adf333 \\
\hline & MUITO FORTE & Terraços Marinhos & 244 & Atm244 \\
\hline \multirow{16}{*}{ 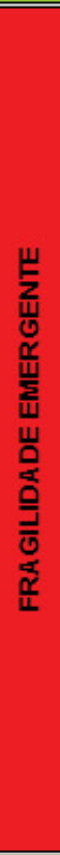 } & & Tabuleiros Pré-litorảneos & 234 & Dt234 \\
\hline & BAIXA & $\begin{array}{l}\text { Atividades } \\
\text { antropogências } \\
\text { (mineração) }\end{array}$ & 233 & $D+233$ \\
\hline & TEEDIA & Terraços Marinhos & 244 & Atm244 \\
\hline & \multirow{5}{*}{ FORTE } & Terraços Marinhos & $333,343,354$ & $\begin{array}{l}\text { Atm333; } \\
\text { Atm343; } \\
\text { Atm354 } \\
\end{array}$ \\
\hline & & Terraços Fluviais & 444 & Atf444 \\
\hline & & Planicies lacustres & 544 & Apl544 \\
\hline & & Tabuleiros pré-litorâneos & 334 & Dt334 \\
\hline & & $\begin{array}{l}\text { Atividades } \\
\text { antropogências } \\
\text { (mineração) }\end{array}$ & 435 & Fam435 \\
\hline & \multirow{8}{*}{ MUITO FORTE } & Faixa de Praia & 555 & Apm555 \\
\hline & & Dunas Móveis & 555 & $\overline{A d m 555}$ \\
\hline & & Dunas Fixas & 554 & Adf554 \\
\hline & & Planície Flúvio-marinha & 555 & Api555 \\
\hline & & Planicie Fluvial & 555 & Apf555 \\
\hline & & Planicie Lacustre & 545 & Apl545 \\
\hline & & $\begin{array}{l}\text { Relevos Vulcânicos } \\
\text { Residais }\end{array}$ & 555 & Dr555 \\
\hline & & $\begin{array}{l}\text { Atividades } \\
\text { antropogências (aterro } \\
\text { sanitário) }\end{array}$ & 545 & Fas545 \\
\hline
\end{tabular}

(1) - A definição numérica dos indicadores segue a seguinte ordem: relevo, solos e cobertura.

A figura 3 apresenta o mapa de fragilidade ambiental, onde é possível verificar a distribuição espacial das unidades de fragilidade potencial e emergente no território. Por intermédio da análise do referido mapa verifica-se que as unidades de fragilidade potencial, portanto, menos frágeis, constituem a unidade de maior dimensão territorial, com cerca de $73 \%$ do território municipal. Estão situadas essencialmente sobre os tabuleiros pré-litorâneos e nos terrenos cristalinos da depressão sertaneja. A primeira (tabuleiros) ocupa praticamente toda a porção central do Município, estendendo-se para o sul, sendo recortada localmente pelas áreas mais frágeis das planícies fluviais e lacustres. 


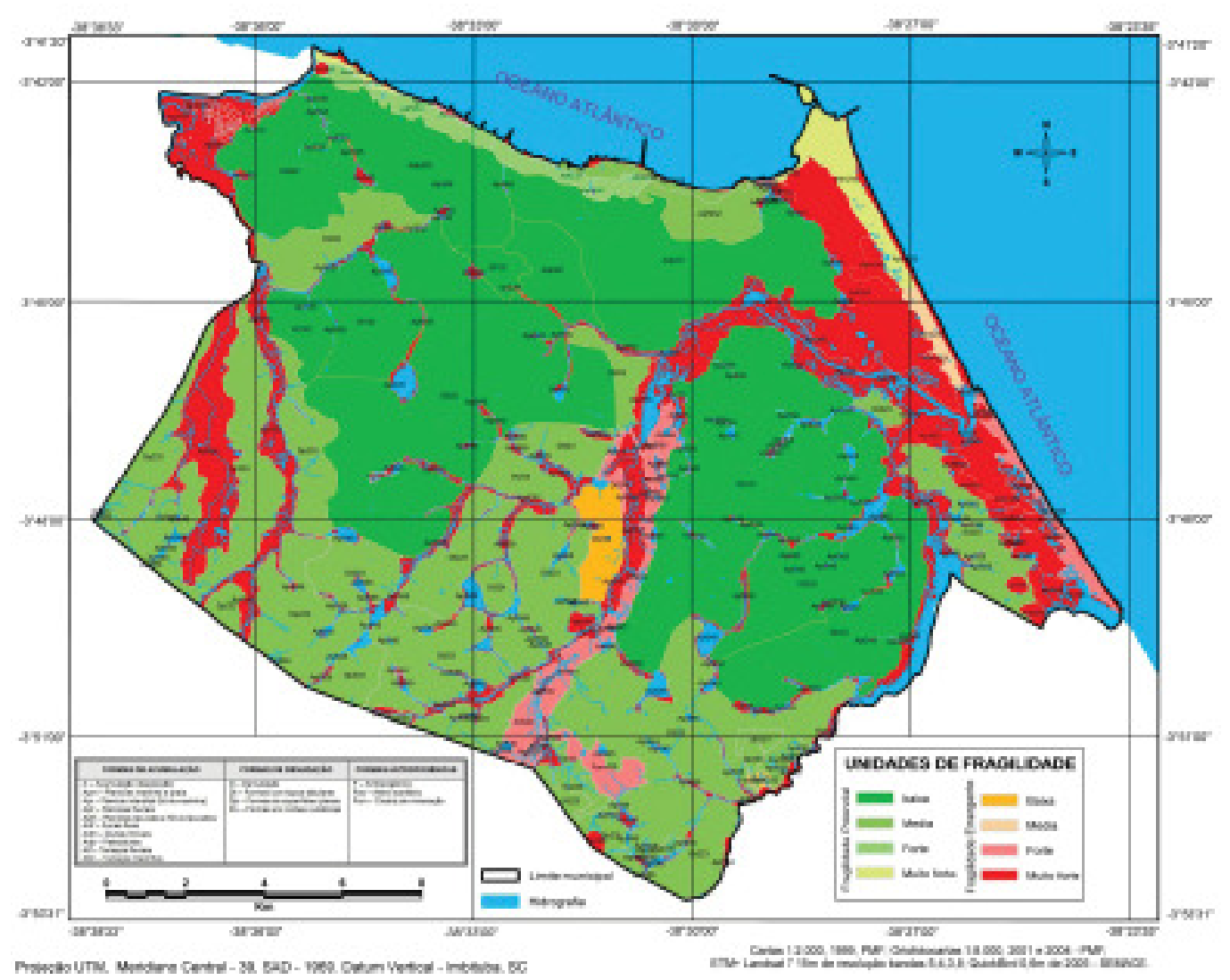

Figura 3 - Mapa de fragilidade ambiental

As áreas de fragilidade potencial nos terrenos cristalinos situam-se na porção meridional, apresentando certa continuidade espacial, estendendo-se desde a porção sudeste ao sudoeste. Neste último, atinge maior penetração em direção N-NO. Ocasionalmente, essas unidades são interrompidas por ambientes mais frágeis das planícies (fluviais e lacustres) e os de maior estabilidade situados sobre os tabuleiros pré-litorâneos.

Ainda quanto à distribuição das unidades de fragilidade potencial em relação à geomorfologia, as exceções são configuradas pelas áreas de paleodunas e dunas fixas (onde os processos de edafização já se consolidaram) que já passaram por avançado estágio de transformação e atualmente se encontram completamente urbanizadas, contando inclusive, com uma boa qualidade de infraestrutura urbana.

Quando se observa a distribuição das unidades de fragilidade emergente, verifica-se que estas correspondem a $27 \%$ do território municipal, com aproximadamente $84,7 \mathrm{~km}^{2}$. Estão concentradas na zona costeira, sobretudo, ao nordeste, na região da Sabiaguaba e ao longo dos principais cursos fluviais, notadamente os rios Cocó e Maranguapinho. São ambientes que originalmente deveriam ser destinados à manutenção da funcionalidade sistêmica, devendo, portanto, ser vedada sua ocupação.

Sobre a concentração dessas unidades nos ambientes de planícies fluviais e lacustres, é importante destacar que são ambientes de extrema fragilidade, constantemente sujeitos a inundações, cuja função primordial é o espraiamento das águas quando dos períodos de maior intensidade pluviométrica, sobretudo, nos eventos de baixa frequência e grande magnitude.

Em função de suas declividades os relevos vulcânicos residuais também são ambientes que apresentam fragilidade ambiental muito forte, sendo, portanto, vedada sua ocupação urbana. Tal fato já ocorre na prática, pois, sobre o Morro Caruru, a atividade predominante é a mineração e o Ancuri está totalmente sendo utilizado como estação elevatória para distribuição de água tratada para o Município.

Com base no que fora constatado acerca da fragilidade, pode-se afirmar que a distribuição dos ambientes mais frágeis segue estreita correlação com a componente geomorfológica, embora já 
tenha sido enfatizado que não é resultado desta, somente. Apesar da diversidade de ambientes que apresentam uma fragilidade emergente forte ou muito forte, a situação mais preocupante se dá nas áreas de planície fluvial e planície flúvio-marinha.

Tal preocupação decorre da elevada situação de fragilidade destes ambientes, que estão susceptíveis à incidência de eventos de grande intensidade e atualmente estão com sua funcionalidade sistêmica comprometida, especialmente as planícies fluviais em decorrência da ocupação urbana descontrolada. A atual situação das planícies fluviais, sobretudo, as situadas sobre os rios Cocó e Maranguapinho configuram as condições necessárias para eclosão de situações extremamente graves, ainda mais quando considerada a vulnerabilidade das populações assentadas nesse ambiente, tema que foi oportunamente tratado em Santos (2011).

\section{CONSIDERAÇÕES FINAIS}

Objetivou-se com este ensaio mostrar uma interpretação de aplicação dos estudos integrados em ambientes que já passaram por significativas mudanças nas paisagens naturais por ocasião da urbanização.

Evidenciou-se que, com as devidas adaptações, a análise da fragilidade ambiental constitui um importante instrumento de avaliação do meio físico-natural, considerando, inclusive as transformações urbanas. Com a investigação conduzida na Cidade de Fortaleza, mostrou-se que a fragilidade ambiental permite identificar no ambiente urbano territórios com diferentes níveis de problemas socioambientais.

A análise de fragilidade em ambientes urbanos constitui ferramenta útil ao planejamento ambiental e ordenamento do território, de modo que possam ser compatibilizadas as atividades produtivas e culturais com a capacidade de suporte dos sistemas socioambientais.

Portanto, referido instrumento de análise fornece importantes subsídios para concretização de um planejamento includente, que distribua de modo mais equilibrado as atividades no território, considerando de um lado as fragilidades ambientais e de outra parte as potencialidades dos recursos ambientais e da sociedade, contribuindo para redução dos problemas socioambientais e das desigualdades socioespaciais.

\section{BIBLIOGRAFIA}

AB'SABER, A. N. Bases conceptuais e papel do conhecimento na previsão de impactos. In: MULLER-PLANTENBERG, G. e AB'SABER, A. N. (orgs.). Previsão de Impactos: o estudo de impacto ambiental no leste, oeste e sul. Experiências no Brasil, na Rússia e na Alemanha. São Paulo: Edusp, 1994.

AB'SABER, A. N. Um conceito de Geomorfologia a Serviço das Pesquisas Sobre o Quaternário. Geomorfologia: GEOG/USP. São Paulo, n. 18, 1969.

ACSELRAD, Henri. Discursos da sustentabilidade urbana. Revista Brasileira de Estudos Urbanos e Regionais. v. 1, p. 79-90, 1999.

ARAÚJO, Gustavo H. de Sousa. et al. Gestão Ambiental de Áreas Degradadas. Rio de Janeiro. Bertrand Brasil, 2005. 320p.

BERTRAND, G. Paisagem e geografia física global: esboço metodológico. Caderno de Ciências da Terra. São Paulo, v.13, p. 1-21, 1969.

BRANDÃO, Ana Ma. P. Macedo. Clima Urbano e Enchentes na Cidade do Rio de Janeiro. In GUERRA, A. T.; et al. Impactos Ambientais Urbanos no Brasil. Rio de Janeiro: Bertrand Brasil, 2001.

BRANDÃO, R. L. Sistema de Informações para a Gestão e Administração Territorial da Região Metropolitana de Fortaleza - PROJETO SINFOR. Mapa geológico: Texto Explicativo. Fortaleza: CPRM, 1995. 34p. CHRISTOFOLETTI, Antonio. Análise de Sistemas em Geografia. Geomorfologia. São Paulo: HUCITEC, 1979. 
CHRISTOFOLETTI, Antonio. Modelagem de Sistemas Ambientais. São Paulo: Edgard Blucher, 1999. 236p. DEMEK, J. Generalização dos mapas geomorfológicos. 1977.

FIERZ, M. M. de S. As abordagens sistêmicas e do equilíbrio dinâmico na análise da fragilidade ambiental do litoral do estado de São Paulo: contribuição à geomorfologia das planícies costeiras. 410f. Tese (Doutorado em Geogafia Física) FFLCH-Departamento de Geografia da Universidade de São Paulo - USP. São Paulo, 2008.

GRIGORIEV, A. A. Os fundamentos teóricos da moderna geografia física. In: The Interaction of Science in the Study of the Earth. Moscou, 1968.

GUERASIMOV, I. Problemas metodológicos de ecologizacion de La ciência contemporânea. In: La Sociedad EI Medio Natural. Moscou: Editorial Progresso, 1980.

MARICATO, Ermínia. Brasil Cidades: alternativas para a crise urbana. 2a ed. Petrópolis: Vozes, 2001. 204p. MECERJAKOV. J. P. Les Concepts de Morphostruture et de Morphoesculture: un novel instrument de l'analysis Geomorfologique. Annales de Geographie. Paris, 1968.

PENCK, Walter. Morphological Analysis of Land Forms: a contribution of physical geology. London: Macmilian, 1953.

PORTO, Marcelo Firpo de Souza. Uma Ecologia Política dos Riscos: princípios para integramos o local e o global na promoção da saúde e da justiça ambiental. Rio de Janeiro: Fiocruz, 2007. 248p.

RODRIGUES, J. M. Mateo., et al. Geoecologia das paisagens: uma visão geossistêmica da análise ambiental. Fortaleza, Editora UFC, 2004, 222p.

ROSS, Jurandyr L. S. Análise empírica da fragilidade empírica dos ambientes naturais e antropizados. Revista do Depto de Geografia da USP. São Paulo. n.8, 1994.

ROSS, Jurandyr L. S. Análises e Sínteses na Abordagem Geográfica da Pesquisa para o Planejamento Ambiental. Revista do Departamento de Geografia da USP. São Paulo. n.9, p.65-75, 1995.

ROSS, Jurandyr L. S. Ecogeografia do Brasil: subsídios para planejamento ambiental. São Paulo: Oficina de Textos, 2006. 208p.

ROSS, Jurandyr L. S. Geomorfologia Aplicada aos EIAs-RIMAs. In: Guerra. Antonio José Teixeira e CUNHA, Sandra Baptista da. Geomorfologia e Meio Ambiente. Rio de Janeiro: BERTRAND Brasil, 2003. p. 291-336.

ROSS, Jurandyr L. S. O Registro Cartográfico dos Fatos Geomórficos e a Questão da Taxonomia do Relevo. Revista do Departamento de Geografia da USP. São Paulo, n.6, 1992.

ROSS, Jurandyr. L. S; FIERZ, M. Matos; AMARAL, Rosângela do. Da Ecodinâmica à Fragilidade Ambiental: subsídios ao planejamento e ordenamento territorial. In: LEMOS, A. I. G. de; ROSS, Jurandyr. L. S; LUCHIARE. A. (orgs). América Latina: sociedade e meio ambiente. São Paulo: Expressão Popular, 2008. p.67-84.

SANTOS, Jader de Oliveira. Fragilidade e riscos socioambientais em Fortaleza-CE: contribuições ao ordenamento territorial. 2011: 331f. Tese (Doutorado em Geografia Física) - Faculdade de Filosofia Letras e Ciências Humanas, Universidade de São Paulo, 2011.

SANTOS, Jader de Oliveira. Vulnerabilidade ambiental e áreas de risco na Bacia hidrográfica do rio Cocó: Região Metropolitana de Fortaleza-CE. 2006. 216 f. Dissertação (Mestrado Acadêmico em Geografia) - Universidade Estadual do Ceará. Fortaleza, 2006.

SANTOS, Milton. A Urbanização Brasileira. $5^{\text {a }}$ ed. São Paulo: Editora da Universidade de São Paulo, 2008. 176p.

SOTCHAVA, V. B. O Estudo dos geossistemas. Métodos em questão. IGEOG/USP. São Paulo, 1976.

SOUZA, Marcos J. Nogueira de. Contribuição ao estudo das unidades morfo-estruturais do Estado do Ceará. Revista de Geologia-UFC. Fortaleza. V. 1. p. 73-91, 1988.

SOUZA, Marcos J. Nogueira de; NETO, J. Meneleu; SANTOS, Jader de Oliveira; GONDIM, Marcelo Saraiva. Diagnóstico Geoambiental do Município de Fortaleza: subsídios ao macrozoneamento ambiental e à revisão do plano diretor participativo - PDPFor. Fortaleza: Prefeitura Municipal de Fortaleza, 2009. 172p. SOUZA, Marcos. J. Nogueira de. Bases naturais e esboço do zoneamento geoambiental do estado do Ceará. 
In: Souza, M.J.N. et. al. (Orgs.) Compartimentação territorial e gestão regional do Ceará. Fortaleza: FUNECE, 2000. p.13-98.

TRICART, J. Ecodinâmica. Rio de Janeiro: IBGE, 1977. 97p.

TRICART, J. Ecogeography and rural management. Longmam Scientific \& Technical. Paris, 1992.

Trabalho enviado em março de 2013

Trabalho aceito em abril de 2013 